\title{
O ensino de filosofia no nível médio: tecnologias digitais e práticas pedagógicas inovadoras
}

\author{
Philosophy teaching at the High School level: \\ digital technologies and innovative pedagogical practices
}

\begin{abstract}
Ademir Aparecido Pinhelli Mendes
Professor Doutor no Centro Universitário Internacional Uninter, Curitiba, Paraná, Brasil. ademir.m@uninter.com - https://orcid.org/0000-0003-4929-9544
\end{abstract}

\section{Fábio Antônio Gabriel}

Professor Doutor na Rede Estadual de Educação do Paraná, Curitiba, Paraná, Brasil. fabioantoniogabriel@gmail.com - https://orcid.org/0000-0002-4990-4102

\section{Arhur Silva Araújo}

Professor na Rede Estadual de Educação do Paraná, Curitiba, Paraná, Brasil.

arthur_40@hotmail.com.br - https://orcid.org/0000-0002-9905-6850

Recebido em 24 de abril de 2020

Aprovado em 29 de junho de 2020

Publicado em 28 de julho de 2020

RESUMO: Este artigo problematiza a contribuição das tecnologias digitais no processo de ensino e de aprendizagem da filosofia no nível médio e tem como objetivo analisar a viabilidade da aprendizagem filosófica mediada por elas. A metodologia para a coleta de dados foi a pesquisa da observação participante de abordagem qualitativa. Foram realizadas observações das aulas de um professor de filosofia, em escola pública estadual do município de Curitiba-PR, por um estudante de filosofia, participante de projeto de iniciação científica, orientado por um pesquisador da área de Educação e Novas Tecnologias. Os resultados da pesquisa evidenciam que o ensino de filosofia no ensino médio pode ser mediado por recursos tecnológicos digitais, envolvendo os sujeitos no processo de ensino e aprendizagem no estudo dos temas filosóficos. No entanto, a inserção das tecnologias digitais torna-se um desafio propriamente filosófico, pois a utilização de tal ferramenta pode modificar o conteúdo e o fazer filosófico, o que, em si, representa um problema filosófico. Palavras-chave: Ensino médio; Ensino de filosofia; Tecnologias digitais; Práticas pedagógicas inovadoras.

ABSTRACT: This article problematizes the contribution of digital technologies in the process of teaching and learning Philosophy at the High School level, and aims to analyze the viability of philosophical learning mediated by them. The methodology for data collection was the participant observation research of a qualitative approach. Observations of the classes of a Philosophy teacher at a state public school in the city 
of Curitiba-Paraná-Brazil were carried out by a Philosophy student, who participates in a scientific initiation project guided by a researcher in the area of Education and New Technologies. The results of the research show that the teaching of Philosophy in High School can be mediated by digital technological resources, involving the subjects in the teaching and learning process in the study of philosophical themes. However, the insertion of digital technologies becomes a real philosophical challenge, because the use of such a tool can modify the content and the philosophical doing, which, in itself, represents a philosophical problem. Keywords: High School; Teaching Philosophy; Digital Technologies; Innovative Pedagogical Practices.

\section{Introdução}

O presente artigo apresenta um relato de experiência sobre o uso das tecnologias digitais no ensino de filosofia no ensino médio, a fim de investigar as suas possibilidades e os limites no ambiente da sala de aula.

As informações para a construção do relato de experiência foram coletadas por meio da pesquisa de observação participante, realizada por um estudante de Licenciatura em Filosofia, em seu estágio supervisionado de observação das aulas de filosofia, ministradas por um professor do ensino médio, em uma escola pública estadual no município de Curitiba-PR.

Observou-se, por um período aproximado de três meses, turmas de $3^{\circ}$ ano, nominadas de $\mathrm{A}$ a $\mathrm{H}$, ou seja, do $3^{\circ} \mathrm{A}$ até $\circ 3^{\circ} \mathrm{H}$ do ensino médio, no período noturno, totalizando oito turmas de $3^{\circ}$ ano, compostas por 246 alunos matriculados em uma instituição de ensino público estadual na cidade de Curitiba.

O professor, titular da disciplina de Filosofia, buscando articular a interação com os alunos nas aulas, recorreu a linguagem de fácil entendimento e compreensão, em nível do mundo juvenil, e inseriu ferramentas tecnológicas para auxiliar a aprendizagem. Dentre as diversas tecnologias digitais, destacaram-se o uso de vídeos (YouTube), o Sway (aplicativo que possibilita a criação de apresentações para a web) e o CmapTools (ferramenta para criar mapas conceituais).

Inicia-se apresentando as possibilidades e os limites da tecnologia no ensino de filosofia, procurando ressaltar as contribuições da tecnologia. Posteriormente, são expostos alguns resultados da observação realizada e, em seguida, as discussões teóricas sobre o ensino de filosofia utilizando tecnologias digitais.

\section{Possibilidades e limites de uso da tecnologia no ensino de filosofia}

Parte-se do pressuposto de que uso das tecnologias digitais na disciplina de filosofia no ensino médio, assim como em outras disciplinas, contribui para o diálogo com os alunos e facilita a pesquisa de informações necessárias ao desenvolvimento do conhecimento filosófico, bem como a valorização de atividades interativas. Tais recursos tecnológicos, quando bem utilizados e conscientemente acessados, permitem ao discente realizar pesquisas, conhecer novos conceitos, viajar pelo espaço virtual sem sair do ambiente escolar, como, por exemplo, conhecer museus, visitar bibliotecas online, visitar lugares históricos importantes para a História da Filosofia. 
É preciso considerar que as práticas educativas no ensino de filosofia contribuem com formação humana e profissional dos estudantes. Contudo, para que isso ocorra, não basta a adoção e uso dos recursos didáticos e tecnológicos no processo pedagógico. É necessário investir cada vez mais nas relações humanas e pessoais, destacando a força do coletivo na solução de problemas filosóficos e na crença de que todos são capazes.

Para Lemos (2015, p. 31), "a evolução da espécie humana é fruto desse movimento perpétuo e infindável, sendo a técnica responsável pela criação da segunda natureza - a cultura - num processo de desnaturalização do homem".

Ao decidir trabalhar com o ensino de filosofia, mais precisamente com novas tecnologias digitais, o docente, como filósofo, depara-se com diversas situações em diferentes contextos habituais ao seu convívio com a educação. Analisando a tecnologia educacional, encontra-se possibilidades que levam a aplicar determinado assunto com facilidade, porém existem também problemas entendidos como limite, articulados ao uso da tecnologia no ambiente escolar.

Como salientam Abreu et al. (2013), ao fazer uso de ferramentas tecnológicas em sala de aula sem refletir sobre as formas e as consequências de sua utilização corre-se o risco de que a educação torne-se cada vez mais instrumental e menos humana, perdendo especialmente suas dimessões éticas e políticas. Assim, nos dias atuais, em que temos diversos recursos tecnológicos à nossa disposição, urge utilizá-los para provocar o pensamento dos nossos interculores que, de forma mais direta, são nossos alunos de filosofia no ensino médio. Os professores de filosofia são convidados a problematizar filosoficamente a utilização das novas tecnologias em aulas de filosofia.

A tecnologia vem, portanto, transformando a sociedade e sendo por ela transformada; também as pessoas e os seus modos de se relacionar-se e comunicar-se alteram-se. Dominar novas tecnologias norteia-se pelo lema de conectar-se com as mudanças que os tempos atuais adotam, ou seja, predispõe cada vez mais ao acesso e ao uso dos recursos tecnológicos relacionados com a educação.

Para D’Ambrósio (2001), é necessário encontrar alternativas para substituir aulas meramente expositivas que mantêm $o$ aluno passivo no processo de ensino e aprendizagem e substituir tais situações por práticas pedagógicas mais dinâmicas, mediadas por recursos que estimulem a participação discente para que o aprendizado efetive-se de forma mais eficiente, mais adequada.

Silva (2007) afirma que, ao desenvolver um trabalho coletivo sobre a utilização de um software para o processo de ensinar e aprender funções em uma escola pública, discute-se a questão de avaliar o trabalho educativo desenvolvido em laboratório de informática como um espaço de produção de saberes discentes que podem propiciar um espaço de formação e desenvolvimento profissional. É necessário estar preparado para tal missão e participar do processo de inclusão das novas tecnologias e dos avanços que nos cercam.

É necessário, primeiramente, tornar o currículo interativo e incentivar o uso dos recursos tecnológicos, ajustados e adaptados ao currículo; porém, respeitando a 
praticidade e atendendo sempre aos objetivos da educação. O que importa é discutir é como essas possibilidades e limites podem afetar a educação e seu processo pedagógico.

As expectativas e os impactos das Tecnologias Digitais de Informação e Comunicação (TDIC) na educação, compreendendo possibilidades e limites, "referem-se a um conjunto de fenômenos e processos que demarcam, presidem ou orientam as políticas de aperfeiçoamento da qualidade da educação, marcando o sentido do conceito de qualidade na educação" (COLL; MONEREO, 2010, p. 67).

Diante dessa visão, vários questionamentos foram lançados ao processo educacional sobre possibilidades e limites da tecnologia na escola. Ainda encontran-se pessoas que não dispõem de conhecimentos específicos para a utilização de tais recursos tecnológicos, o que se apresenta como empecilho para o sucesso no processo educacional.

Cada recurso tecnológico tem suas possibilidades e limites. Conforme Moore e Kearsley (1996), um dos piores equívocos que um docente pode cometer no processo educacional é escolher apenas um meio. A escolha dos recursos adequados deve ser realizada para cada curso, para cada programa: cada um tem seus diferentes objetivos, diferentes alunos e diferentes ambientes de aprendizagem.

De acordo com Litwin (1997), recursos tecnológicos aplicados à educação, assim como a didática, estão voltados à prática de ensino, mas vão além, pois incluem, entre suas preocupações, o exame da teoria da comunicação e dos novos desenvolvimentos tecnológicos: a informática, o vídeo, a TV, o rádio, o áudio, o celular, impressos, internet etc.

Para Moran (1997), uma das vantagens oferecidas pelo uso da internet em sala de aula é que ela permite o acesso a fontes inesgotáveis de informação, servindo de estímulo para os alunos na realização de suas pesquisas, pois, por meio dos acervos de livros eletrônicos das bibliotecas virtuais, é possível acesso a valiosos conteúdos, que favorecem o enriquecimento de conhecimentos e o desenvolvimento dos trabalhos com mais agilidade. Moran (2013, p. 31) vai mais longe ao propor que o uso das tecnologias contribua diretamente na emergência de novas metodologias que possibilitarão novas formas de lecionar:

Como conciliar mobilidade e espaços e tempos previsíveis? Por que precisamos estar sempre juntos para aprender? A escola precisa entender que uma parte cada vez maior da aprendizagem pode ser feita sem estarmos em sala de aula e sem a supervisão direta do professor. Isso assusta, mas é um processo inevitável. Em vez de sermos contrários, por que não experimentarmos modelos mais flexíveis? Por que obrigar os alunos a irem à escola todos os dias e repetirem os mesmos rituais nos mesmos lugares? Isso não faz mais sentido. A organização industrial da escola em salas, turmas e horários é conveniente para todos - pais, gestores, professores, governantes -, menos para os mais diretamente interessados, os alunos.

Entendemos a importância das tecnologias no ensino de filosofia, porque elas podem contribuir para que o estudante tenha uma recepção da filosofia de modo a refletir sobre o próprio sentido da vida. Heller (1983) tematiza a importância de refletirmos sobre uma recepção completa da filosofia. Uma recepção completa da filosofia envolve harmonia entre 
pensar, viver e agir. Acredita-se que se o professor de filosofia aproximar-se do universo digital com que o estudante está habituado será mais fácil propiciar-lhe uma experiência filosófica em que absorva não apenas teoricamente, mas vivencialmente a filosofia em sua existência. Conforme já apontado é de fundamental importância que o licenciando, já na licenciatura, vivencie a experiência de utilizar as ferramentas tecnológicas para que, quando assumir como professor, tenha condições de ensinar filosofia utilizando-se de ferramentas tecnológicas.

Embora existam grandes limitações no que se refere à inserção de ferramentas tecnólgicas digitais na educação, em especial no ensino de filosofia, observa-se que há uma forte tedência para que isso ocorra. Mas será que a profissão professor vai desaparecer? Acredita-se que não. Sempre serão necessários mediadores que viabilizem o aproveitamento dos recursos tecnológicos disponíveis na sociedade em que vive-se. Talvez desapareça o modelo do professor que escrevia no quadro, pedia que os alunos copiassem e depois oferecia um questionário para eles decorarem para a avaliação. Nesse contexto, o professor de filosofia é convidado a utilizar-se dos recursos tecnológicos da melhor maneira possível, com o intuito de mediar a aprendizagem. Não se pode ver os recursos tecnológicos como inimigos, mas como amigos que podem contribuir significativamente para agregar melhores condições de aprendizagem para nossos alunos. Nessa perspectiva, Moran (2013, p. 31) auxilia-nos a pensar em possíveis novas formatações da sala de aula:

Os espaços se multiplicam, mesmo que não saiamos do lugar
(múltiplas atividades diferenciadas na mesma sala). As salas de
aula podem tornar-se espaços de pesquisa, de desenvolvimento
de projetos, de intercomunicação on line, de publicação, com a
vantagem de combinar o melhor do presencial e do virtual ao mesmo
tempo. Com isso é possível pesquisar de todas as formas, utilizando
todas as mídias, todas as fontes, todas as maneiras de interação.
Pesquisar às vezes todos juntos, ou em pequenos grupos, ou mesmo
individualmente. Pesquisarnaescola ou em diversosespaçosetempos.
Combinar pesquisa presencial e virtual. Relacionar os resultados,
compará-los, contextualizá-los, aprofundá-los, sintetizá-los.

Nessa nova conjuntura, o professor assume novos papéis: pode auxiliar os estudantes a buscarem sites confiáveis para desenvolver suas pesquisas; pode partilhar conhecimentos de pesquisas mais aprofundadas que realizou; pode orientar leituras de livros; pode, mesmo, valer-se de aulas expositivas quando trabalha assuntos não disponíveis na internet (MORAN, 2013). Assim, vive-se em tempos de ruptura de paradigmas no âmbito das questões educacionais. E ve-se o quanto esse novo modelo é emergente. Diante da recente pandemia do coronavírus (em 2020), percebe-se o quanto as instituições que dispõem de plataforma de ensino a distância se destacaram-se, podendo manter as atividades de estudo dentro da normalidade, porque já estavam habituadas ao processo ensino-aprendizagem para além das paredes das salas de aula. Behrens (2013, p.73) apresenta a necessidade de não apenas os professores modificarem sua forma de ensinar filosofia, mas também os próprios alunos se adequarem-se, realizando modificações no modo de buscar, de explorar conhecimentos: 
Por sua vez, o aluno precisa ultrapassar o papel de passivo, de escutar, de ler, decorar e de repetidor fiel dos ensinamentos do professor e tornar-se criativo, crítico, pesquisador e atuante, para produzir o conhecimento. Em parceria, professores e alunos precisam buscar um processo de auto-organização para acessar a informação, analisar, refletir e elaborar com autonomia e conhecimento. O volume de informações não permite abranger todos os conteúdos que caracterizam uma área de conhecimento. Portanto, professores e alunos precisam aprender a aprender como acessar a informação, onde buscá-la e o que fazer com ela.

Desse modo, entende-se que é de grande importância que o ensino de filosofia possa, paulatinamente, adequar-se aos novos desafios do aprender e do ensinar, como, por exemplo, a iniciativa de professores que colocam suas aulas gravadas no YouTube, contribuindo assim para que a filosofia ultrapasse as próprias barreiras do âmbito escolar, possibilitando que até mesmo pessoas que não dispuseram de aulas de filosofia na formação no ensino médio, contem agora com a possibilidade de contato com a filosofia.

Para Moran (2013, p. 71) é necessário pensar a respeito da importância de não sermos resistentes às novas mídias e procurar utilizá-las da maneira mais profícua possível, buscando sempre aperfeiçoar as relações de ensino e aprendizagem:

Ensinar com as novas mídias será uma revolução se mudarmos simultaneamente os paradigmas da educação escolar, que mantém distante professores e alunos. Caso contrário, só conseguiremos dar-lhe um verniz de modernidade, sem mexer no essencial. A internet $\mathrm{e}$ as tecnologias digitais móveis trazem desafios fascinantes, ampliando as possibilidades e os problemas, num mundo cada vez mais complexo e interconectado, que sinaliza mudanças muito profundas na forma de ensinar e aprender, formal e informalmente, ao longo de uma vida cada vez mais longa.

De acordo com Tajra (2001, p. 156), "os jovens devem ser estimulados a localizar as informações, a tratá-las e criticá-las e, por fim, a se comunicar". Assim, utilizar a internet no campo educacional, trabalhando com a tecnologia em sala de aula, evidencia a necessidade de atribuir a maior atenção possível e com muita relevância aos processos pelos quais os professores optam por trabalhar, valendo-se de um recurso para a inovação pedagógica, em sala de aula, para gerar benefícios ao processo ensino-aprendizagem, podendo, então, mais eficientemente cumprir metas, aliando o útil ao agradável.

Segundo as Diretrizes Curriculares Nacionais, concretamente, o projeto políticopedagógico das unidades escolares que ofertam o ensino médio deve considerar: "VIII - utilização de diferentes mídias como processo de dinamização dos ambientes de aprendizagem e construção de novos saberes" (BRASIL, 2012, Cap. VIII).

Tal observação das Diretrizes Curriculares para o ensino médio enfatiza a construção da necessidade de uso dos recursos tecnológicos em sala de aula, já que expressiva maioria de estudantes dispõe de acesso a celulares, tablets, notebooks, dentre outros. 
Os estudos em relação à tecnologia em sala de aula indicam o uso de recursos tecnológicos, tais como: lousas digitais, computadores em laboratórios de informática, aplicativos, dentre outros, que, infelizmente, nem sempre estão acessíveis e/ou disponíveis para todas as escolas e, diretamente, em posse dos alunos para uso e estudo.

Nesse sentido, é importante que os educadores trabalharem com os alunos fazendo uso de dispositivos móveis, como o celular, que muitos alunos utilizam para acesso à internet. As tecnologias digitais mediadas potencializam a prática de ensino de filosofia no ensino médio, pois cada recurso tecnológico tem aplicação de acordo com os assuntos de interesse do aluno-professor. Dentre esses recursos, é possível citar o vídeo (YouTube, que é uma plataforma de compartilhamento de vídeos), o Sway (aplicativo que permite a criação de apresentações para a web, evolução do PowerPoint) e o Cmaptools (ferramenta para criar mapas conceituais).

Kenski (2012) destaca que o mundo digital não é uma panaceia, é um novo mundo com seus problemas também presentes, desde hackers que invadem sistemas e criam problemas de manutenção, até a possibilidade de uso indevido de conteúdos disponíveis na rede, como por exemplo, o uso de plágios em trabalhos acadêmicos. Assim afirma Kenski (2012, p. 53):

\footnotetext{
As novas tecnologias digitais não oferecem aos seus usuários um novo mundo, sem problemas. Estamos no início de uma nova e revolucionária era tecnológica e pagamos um preço alto pelo pioneirismo. Ainda não se tem ideia das consequências e repercussões que as articulações em rede e ampliação da capacidade tecnológica de acesso vão ocasionar e do que poderão oferecer em um curto prazo. O que temos certeza é que independentemente dos avanços, as tecnologias ainda durante um bom tempo vão continuar a nos trazer alguns problemas individuais e coletivos para resolver.
}

Kenski (2012) entende que as tecnologias digitais devem colaborar para a intensificação das oportunidades de aprendizagem. Nos dizeres da autora: "o desafio é o de inventar e descobrir usos criativos da tecnologia educacional que inspirem professores e alunos a gostar de aprender, para sempre" (KENSKI, 2012, p. 67). Nesse contexto, os professores de filosofia são convidados a utilizar cada vez mais os recursos tecnológicos com o objetivo de otimizar os resultados de uma aprendizagem profícua na vida dos estudantes. Os recursos tecnológicos são cada vez mais bem-vindos, na medida em que auxiliem os alunos a filosofar.

Gallo (2012) trabalha a importância de que a aula de filosofia efetive-se enquanto uma oficina de conceitos. Tal autor fundamenta-se na filosofia de Deleuze e Guattari (1992) para afirmar a importância de criar conceitos sempre novos no exercício filosófico. Acredita-se que os ambientes digitais podem contribuir para um ensino de filosofia que se efetive enquanto oficina de conceitos, na medida em que possibilita uma interação do estudante por meio dos recursos digitais com os conceitos filosóficos. Caso os professores de filosofia utilizem 
recursos digitais em suas aulas aumentam as chances de possibilitar um ensino de filosofia que ultrapasse a mera memorização de conceitos filosóficos. Uma das grandes virtudes dos recursos digitais é possibilitar a interação entre alunos e os conteúdos filosóficos.

Bennetti (2006) também, a partir de uma leitura do ensino de filosofia mediado por Lacan (1985) e, Deleuze e Guatarri (1992) recomenda a importância de não romantizar o ensino de filosofia, entendendo que os jovens por natureza desejam pensar. Pensar é um desafio e é o trabalho do professor de filosofia procurar contribuir para despertar o desejo dos alunos para pensar. Entendemos que a filosofia não é a única disciplina que contribui para pensar, mas sua contribuição é significativa no sentido de possibilitar um pensar por conceitos.

Jaspers (1971) contribui para novas reflexões sobre as motivações para que um espírito antifilosófico não permeie a sociedade. Nesta perspectiva, acredita-se que, quanto mais os professores de filosofia possibilitarem que o ensino de filosofia ocorra mediado por conceitos, mais chances de fazer a filosofia ser conhecida teremos. Outrossim, acredita-se que o grande responsável pelo ensino filosófico é o professor de filosofia que, conforme Carrilho (1987), é convidado aser professor-filósofo, na medidaem que seja alguém que vivencia, em sua existência, uma experiência do filosofar para que possa contribuirajudando seusalunos a também filosofarem.

Passa-se agora para o relato da experiência observada, procurando dialogar com os dados empíricos.

\section{Metodologia: relato da experiência observada}

A observação das aulas iniciou-se no momento em que o professor de filosofia organizou um trabalho, no qual os alunos deveriam escolher um filósofo moderno ou contemporâneo e estudar o tema da ética e da política. O professor ofereceu uma relação de filósofos que poderiam ser trabalhados: Foucault, Sartre, Hobbes, Locke, Rousseau, Kant, Hegel, Voltaire, Marx e Engels, Adam Smith, Stuart Mill, Bakunin, Nietzsche, Habermas, Simone de Beauvoir e Hanna Arendt.

Cada grupo de alunos, formado por quatro integrantes, deveria estudar a concepção ética e política de um dos filósofos, escolhido por sorteio em sala de aula, construindo um mapa conceitual com o aplicativo Cmaptools e produzindo um vídeo, incluindo os seguintes pontos: contexto histórico do filósofo, vida e obra e concepção ética e política. Na produção e na apresentação do mapa conceitual e do vídeo, os alunos deveriam demonstrar domínio do conteúdo sobre o filósofo estudado, pois seriam atribuídas notas a tal tarefa para compor a avaliação trimestral.

Após a organização dos trabalhos, as aulas seguintes foram realizadas no laboratório de informática, nas quais os alunos deram início à construção da pesquisa proposta com a organização de um mapa conceitual referente ao tema que cada grupo deveria desenvolver. Os alunos também puderam consultar textos e vídeos obtidos nas pesquisas em sites e em artigos científicos. Com essa atividade, foi possível observar como o aluno pode tornar-se pesquisador, fazendo uso dos recursos tecnológicos disponíveis de forma interativa sob a orientação de um professor. 
Durante as aulas no laboratório de informática, observou-se que os alunos, organizados em grupos, ao realizarem as pesquisas sobre o filósofo escolhido, debatiam entre si e, quando necessário, chamavam o professor para dirimir dúvidas, ocorrendo o aprofundamento do conteúdo pesquisado. Por meio dessa metodologia, os alunos participavam das aulas de forma interativa com os colegas, fazendo uso dos recursos tecnológicos, orientados pelo professor.

$\mathrm{Na}$ etapa seguinte, o professor disponibilizou a cada grupo excertos de textos do filósofo pesquisado. Para isso, utilizou como recurso tecnológico um aplicativo denominado Sway (aplicativo que permite mostrar fotos e textos em blog). Nessa etapa, os alunos foram motivados pelo professor para que lessem os excertos de textos disponibilizados, a fim de aprimorar o processo de pesquisa iniciado no laboratório de informática. Em sala de aula, os alunos puderam acessar o Sway pelo aparelho celular e ler os textos dos filósofos selecionados pelo professor. Por meio da leitura dos textos e sob orientação do professor, os alunos acrescentaram conceitos retirados dos textos aos mapas conceituais em construção.

Nas aulas seguintes, os alunos apresentaram à turma os mapas conceituais que foram construídos com a pesquisa. No processo de apresentação, realizado sob a mediação do professor, surgiram dúvidas acerca do filósofo estudado e dos textos lidos. Esclarecendo dúvidas dos alunos, o professor mobilizou a participação da turma e, do começo ao fim, a aula tornou-se instigante, com diversos alunos apresentando pontos de vista sobre determinado assunto abordado. Instalou-se um diálogo dos alunos com o professor e entre alunos, tendo o professor como mediador, falando do filósofo em todos os sentidos: ético, político, cultural etc. A dinâmica repetiu-se por aulas seguidas, sempre com um filósofo diferente, de acordo com a organização encaminhada pelo professor no início dos trabalhos.

Após o processo de pesquisa, construção e apresentação dos mapas conceituais acerca de cada um dos filósofos estudados pelos grupos, o professor marcou a data para apresentação dos vídeos produzidos pelos alunos acerca do filósofo em questão. O vídeo deveria respeitar um lapso de tempo, de cinco a sete minutos e, além de apresentar a vida e obra do filósofo, deveria apresentar também o contexto histórico no qual ele inseria-se, o problema ético e político por ele investigado, suas teses principais e a relação do pensamento do filósofo com um problema filosófico atual.

Nas aulas seguintes, os grupos de alunos apresentaram os vídeos produzidos por eles e novamente foi instalado, em sala de aula, um processo de discussão e de debate sob a mediação do professor, tendo como foco a ética e a política do filósofo estudado.

Observou-se que o professor domina não apenas os conteúdos filosóficos para ministrar aulas no ensino médio com calma e clareza, mas também o uso dos recursos tecnológicos no ensino de filosofia. A escolha dos recursos tecnológicos - como o computador no laboratório de informática, o Cmaptools para a construção de mapas conceituais, e o Sway para disponibilização de materiais - tornou as aulas dinâmicas e interativas, fazendo com que os alunos demonstrassem interesse em estudar a filosofia.

Avalia-se que o professor realiza constantemente o exercício da ação-reflexãoação com os alunos por meio dos trabalhos desenvolvidos, apresentados e discutidos em sala. O professor é um observador dos alunos e, ainda, de suas próprias aulas, a fim de 
identificar as dificuldades no desenvolvimento da aprendizagem durante as realizações das atividades pelos alunos. E aquele é o momento certo para fazer as intervenções e, principalmente, saber quem está aprendendo de forma satisfatória todos os conteúdos propostos em sala de aula.

\section{Análises e reflexões a partir dos dados empíricos}

Kenski (2012) destaca que, a partir do advento das tecnologias de comunicação e de informação vem ocorrendo grandes impactos na educação das novas gerações. Nesse sentido, a autora entende que cada vez mais somos desafiados a utilizar o mundo virtual para contribuir com o aprendizado dos alunos. A partir das aulas observadas, percebe-se o quanto o professor utiliza-se das tecnologias como também estimula a pesquisa vinculada ao uso delas. Nessa perspectiva, de fundamental importância faz-se a exposição dos alunos demonstrando que o papel da presença humana ainda é necessária para a concretização das etapas de ensino-aprendizagem. O professor observado também foi muito feliz quando possibilitou as exposições em grupo, articulando, assim, o desenvolvimento da capacidade de agir em grupo e o trabalho em equipe. Pode parecer algo banal esse quesito, mas é muito importante, porque é por meio desse procedimento que pode-se romper com o individualismo reinante na sociedade contemporânea. Conforme é proposto por Kenski (2012, 2002 p. 96), urge que ampliemos os espaços virtuais de aprendizagem no sentido de maximizar o ambiente de sala de aula:

No ambiente virtual, a flexibilidade da navegação e as formas síncronas e assíncronas de comunicação oferecem aos estudantes a oportunidade de definirem seus próprios caminhos de acesso às informações desejadas, afastando-se de modelos massivos de ensino e garantindo aprendizagens personalizadas. As características tecnológicas do ambiente virtual devem garantir o sentimento de telepresença, ou seja, mesmo que os usuários estejam distantes e acessem o mesmo ambiente em dias e horários diferentes, eles se sintam como se estivessem fisicamente juntos.

Um dos desafios enfrentados pelos professores de filosofia consiste em problematizar filosoficamente os conteúdos curriculares, fazendo uso das mediações tecnológicas que têm à disposição para que a aula de filosofia torne-se um espaço de laboratório conceitual, conforme Carrilho (1987). Quando planeja-se uma aula como laboratório de problematização conceitual, é fundamental a pensar na importância de considerar a aula de filosofia como uma oficina de conceitos, em que o estudante tem a possibilidade de criar conceitos e/ou avaliar o 'valor' dos valores (GABRIEL, 2017). Nesse sentido, é importante que a filosofia supere um mero descritivismo teórico e torne-se uma possibilidade de reflexão e criação de conceitos. Horn (2009) aponta para o fato de que a filosofia é convidada a contribuir com uma reflexão radical sobre os objetos e, também, ela tem uma especificidade no âmbito das 
ciências humanas: uma práxis filosófica. Nos dizeres de Horn (2009, p. 17) sobre práxis filosófica: "a Filosofia, só adquire sentido quando entendida a partir da pólis e esta, por sua vez, é o espaço em que o cidadão conquista sua cidadania, é o espaço da formação humana"

Moraes (2014) registra a vivência da construção de um blog para colaborar com a aula de filosofia, evidenciando a importância dessa ferramenta, para socialização dos conteúdos de filosofia não apenas para alunos, mas para diversas pessoas que se inter-relacionam com os estudantes. A autora entende a importância de utilizar tecnologias que possam atender de forma mais profícua os nossos alunos que são nativos digitais. Nos dizeres da autora:

Em função da constante evolução das TIC e da cultura da internet, com todas as possibilidades de interação, comunicação e informação, certamente o professor de filosofia vê-se implicado em uma situação que demanda o enfrentamento de alguns impasses de cunho didático-pedagógico (MORAES, 2014, p. 20).

Moraes (2014, p. 51) problematiza, no contexto do ensino de filosofia, que a dificuldade dos professores de filosofia em trabalhar com as TIC decorre da ausência de uma formação consistente na licenciatura que possibilite aos futuros docentes terem um domínio do uso pedagógico das TIC:

A formação do professor de filosofia, na maioria dos casos, se dá com foco nos conteúdos filosóficos e na obras que trazem o pensamento dos filósofos. Em contrapartida, são muito poucas as disciplinas que tratam especificamente sobre as questões didático-pedagógicas.

Nas aulas observadas, percebeu-se um esforço do professor em problematizar as questões filosóficas com a prática política, não no sentido partidário do termo, mas, no sentido próprio aristotélico, de que o ser humano é um zoon politicon, ou seja, animal político por excelência. Nessa perspectiva, a formação para a cidadania é um dos pilares das contribuições da filosofia para os estudantes, na medida em que procura apresentar como se pensaram os filósofos da tradição com relação ao exercício da cidadania (HORN, 2009). Nesse sentido, na concepção de Horn (2009, p. 95),

O papel formador da teoria crítica enquanto Filosofia da práxis considera a reflexão como elaboração conceitual crítica comprometida com a superação da realidade opressora, superação da barbárie, da redução da teoria do determinismo da experiência, ou seja, a prática social tem supremacia na dinâmica histórica. Esse entendimento é próprio do pensar dialético que busca explicitar as relações entre conhecimento, poder e dominação.

Considera-se, neste particular, a importância de que a filosofia, ao mesmo tempo em que se utiliza das tecnologias, lance um olhar crítico para o advento da técnica, no sentido de 
que a mecanização das relações de trabalho produz, muitas vezes, desemprego. No cenário do $\mathrm{EaD}$, percebe-se que grandes coorporações da rede de educação tendem a utilizar-se da técnica, não como um serviço na educação, mas parecem ter como única meta o lucro no âmbito das relações educacionais e, nesse contexto, consideram a educação mais como uma mercadoria do que uma relação humana entre professor e aluno dentro da reciprocidade de aprender e ensinar.

Pensa-se a aula de filosofia como meio de contribuir para que os estudantes repensem e ressignifiquem seus próprios valores após dialogar com a tradição filosófica estudada (GABRIEL, 2017). O advento das tecnologias vem somar forças ao processo ensinoaprendizagem, mas o professor continua sendo o grande responsável pelo processo de ensinar, e depende muito dele a potencialidade de buscar refletir sobre o próprio ensino de filosofia mediado pelas tecnologias. Gabriel (2017) defende a importância de que, já na licenciatura, o futuro professor de filosofia vivencie uma experiência do filosofar para que, mais tarde, no campo de trabalho como professor, consiga realizar o ideal proposto por Carrilho (1987): o professor-filósofo. Ser professor-filósofo é um desafio, porque se trata de não ser apenas alguém que ensine descritivamente a filosofia, mas que consiga transmitir a filosofia de maneira a provocar o questionamento e a reflexão nos seus interlocutores. Horn e Mendes (2016) asseveram que o ensino de filosofia poderá ser genuinamente filosófico quando possibilitar aos sujeitos da aprendizagem a recepção filosófica completa, de maneira que o receptor a vivencie completamente e desenvolva a atitude filosófica radical indagando: como devo pensar? Como devo viver? Como devo agir? (HELLER, 1983).

Obiols (2002, p. 131) afirma que "o ensino de filosofia no nível médio deve estar apoiado em algumas das preocupações que, de modo claro ou confuso, estão presente na vida dos jovens, que para além das diferenças sociais e culturais". Nesse sentido, entende-se que as tecnologias digitais muito podem contribuir para que o professor de filosofia tenha contato com a realidade dos educandos, uma vez que as novas gerações já nascem imersas no mundo da tecnologia, muito embora tenham dificuldade para procurar filtrar as informações e os conhecimentos. Seja como for, os desafios são grandes e pretende-se, em futuras investigações, aprofundar reflexões e pesquisas empíricas sobre o ensino de filosofia, procurando responder a questionamentos importantes no âmbito de uma didática do ensino de filosofia que valorize as tecnologias digitais.

\section{Considerações finais}

Ao professor, mediador em sala de aula, cumpre a tarefa de estimular o desenvolvimento sociocultural dos seus alunos nos mais diversos contextos do processo de ensinoaprendizagem, pois a ele cabe argumentar, debater, questionar e apresentar desafios durante a aula. Dessa forma, o aluno aprende a construir as próprias motivações para enfrentar as situações de sua vida.

A maior preocupação do professor é saber se a aula está contemplando os objetivos propostos, relacionando os assuntos relatados nas aulas, tendo a tecnologia como uma 
ferramenta para o debate filosófico. Atuar em sala de aula com jovens utilizando textos filosóficos cobrados no ensino médio é o valioso recurso de que o professor faz uso para motivar o aluno a interessar-se pela exploração de possibilidades, o que remete à apropriação de conhecimentos dos estudos filosóficos, com a corroboração das tecnologias, de tais situações, emergindo aprendizagens significativas, prazerosas e eficazes.

Dentro desse contexto desafiador das práticas educativas, percebeu-se o despertar de uma nova responsabilidade dos docentes: mediadores, nesse papel, no processo de apropriação, de descoberta, de construção e de elaboração de conhecimentos de filosofia. Além disso, também cabe ao professor fazer a mediação da construção de novos conhecimentos, transferência e aplicação, de forma a redimensionar a prática, auxiliada pela capacitação no uso das tecnologias digitais, como ferramentas pedagógicas que evidenciam uma gerência eficaz e adequado controle da aprendizagem.

A reflexão sobre o uso das tecnologias digitais como ferramentas das práticas educativas, além de possibilitar a aprendizagem da utilização de tais recursos, articula a construção favorável no processo de ensino e aprendizagem na disciplina de Filosofia, em que essas novas mídias e tecnologias podem tornar-se recursos didáticos eficazes no processo de produção do conhecimento. Então, é imprescindível que o atual sistema educacional valorize e utilize tais tecnologias digitais para promover formas de desenvolver processos de aprendizagem mais significativos ao contexto dos alunos. No caso específico do ensino de filosofia, o desafio que se apresenta está para além de usar recursos tecnológicos para facilitar a transmissão e assimilação de conteúdos curriculares como deve ocorrer em todas as disciplinas. Importa, ainda, que os recursos utilizados no processo de ensino e aprendizagem não deturpem, ou até mesmo impeçam, a recepção filosófica completa, capaz de assegurar o uso do método filosófico e o desenvolvimento da atitude filosófica pelo jovem no ensino médio.

O presente estudo é de natureza ainda bastante inicial e, para que se possam inferir conclusões mais amplas e definitivas, será necessário ampliar o experimento para outras turmas de alunos de ensino médio e outros professores, o que indica possibilidades futuras para o desenvolvimento de novas pesquisas sobre o tema.

\section{Referências}

ABREU, C. N.; EISENSTEIN, E.; ESTEFENON, S. G. B. Vivendo esse mundo digital: impactos na saúde, na educação e nos comportamentos sociais. Porto Alegre: Artmed, 2013.

ALMEIDA, M. E. Prolnfo: informática e formação de professores - v. 1; Brasília: MEC/ Secretaria de Educação a Distância, 2000.

BENETTI, C. C. Filosofia e ensino, singularidade e diferença: entre Lacan e Deleuze. ljuí: Unijuí, 2006.

BEHRESNS, M. A. Projetos de aprendizagem colaborativa num paradigma emergente. In: MORAN, J. M.; MASETTO, M. T.; BEHRENS, M. A. (org.). Novas tecnologias e mediação pedagógica. 21. ed. Campinas: Papirus, 2013. Cap. 2. p. 73-141. 
BRASIL. Conselho Nacional de Educação. Resolução CNE/CEB n ${ }^{\circ} 2$, de 30 de janeiro de 2012. Diretrizes Curriculares Nacionais para o Ensino Médio. Diário Oficial da União, Brasília, 31 jan. 2012, Seção 1, p. 20.

CARRILHO, Manuel M. Razão e transmissão da Filosofia. Lisboa: Casa da Moeda, 1987.

COLL, C.; MONEREO, C. Psicologia da educação virtual. Porto Alegre: Artmed, 2010.

D’AMBRÓSIO, U. Educação matemática: da teoria a prática. Campinas: Papirus, 2001.

DELEUZE, G.; GUATTARI, F. O que é a filosofia? Tradução de Bento Prado Jr. e Alberto Alonso Muñoz. Rio de Janeiro: 34, 1992.

GABRIEL, F. A. A aula de filosofia enquanto experiência filosófica: possibilitar ao estudante de filosofia "criar conceitos" e ou "avaliar o valor dos valores". Rio de Janeiro: Editora Multifoco, 2017.

GALLO, S. Metodologia do ensino de Filosofia: uma didática para o Ensino Médio. Campinas/SP: Papirus, 2012.

HELLER, A. A Filosofia radical. Tradução Carlos Nelson Coutinho. São Paulo: Brasiliense, 1983.

HORN, G. B. ; MENDES, A. P. P. Ensino de Filosofia: método e recepção filosófica em Agnes Heller. Educar em Revista. Curitiba, n. 62, out./dez. 2016. Disponível em: https:// www.scielo.br/scielo.php?script=sci_arttext\&pid=S0104-40602016000400279\&lng=pt\&tln g=pt. Acesso em: 11 jun. 2020.

HORN, G. B. Ensinar filosofia: pressupostos teóricos e metodológicos. ljuí: Ed. Unijuí, 2009.

JASPERS, K. Introdução ao pensamento filosófico. Tradução Leônidas Hegenberg e Octanny Silveira da Mota. São Paulo: Cultrix, 1971.

KENSKI, V. M. Educação e tecnologias: o novo ritmo da informação. Campinas: Papirus, 2012.

LACAN J. O seminário, livro 11: os quatro conceitos fundamentais da psicanálise (M. D. Magno, Trad.). Rio de Janeiro: Jorge Zahar, 2015.

LEMOS, A. Cibercultura: tecnologia e vida social na cultura contemporânea. Porto Alegre: Sulina, 2015.

LITWIN, E. Tecnologia educacional: política, história e propostas. Porto Alegre: Artes Médicas, 1997.

MOORE, M.; KEARSLEY, G. Distance Education - A Systems View. Belmont: Wadsworth, 1996.

MORAES, S. B. A. Ensino de Filosofia e as TIC: reflexões a partir de experiências do PIBID Filosofia da UFSM. Dissertação (Mestrado em Educação) - Programa de Pós-graduação em Educação. Universidade Federal de Santa Maria, Santa Maria-RS, 2014. MORAN, J. Como utilizar a Internet na educação. Ciência da Informação, v. 25, n. 02, 1997.

MORAN, J. M. Ensino e aprendizagem inovadores com apoio de tecnologias. In: MORAN, J. M.; MASETTO, M. T.; BEHRENS, M. A. (org.). Novas tecnologias e mediação 
pedagógica. 21. ed. Campinas: Papirus, 2013. Cap. 1. p. 11-72.

OBIOLS, Guillermo. Uma Introdução Ao Ensino da Filosofia. Ijuí: Ed. Unijuí, 2002.

SILVA, J. C. Informática e cultura profissional: o laboratório de informática da escola como espaço de formação. In: FONSECA, S. G. Currículos, saberes e culturas escolares.

Campinas: Editora Alínea, 2007.

TAJRA, S. F. Informática na Educação: novas ferramentas pedagógicas para o professor da atualidade. 3. ed. São Paulo: Érica, 2001.

\section{Correspondência}

Ademir Aparecido Pinhelli Mendes - Rua Riachuelo, 110, apto 3009, bairro Centro, CEP: 80.020250, Curitiba, Paraná, Brasil.

\section{(c) (1) (9)(2)}

This work is licensed under a Creative Commons Attribution-NonCommercial 4.0 International (CC BY-NC 4.0) 
